\title{
Hereditary cerebral haemorrhage with amyloidosis, Dutch type (HCHWA-D): clinicopathological studies
}

\author{
A R Wattendorff, B Frangione, W Luyendijk, G T A M Bots
}

\begin{abstract}
Clinical and neuropathological findings are reported in 63 patients with hereditary cerebral haemorrhage with amyloid angiopathy. Patients had mostly recurrent strokes, and at least $80 \%$ of these were haemorrhages. Almost a third of the patients died within a year of their first and only recorded haemorrhage, half of them within two weeks. This angiopathy was restricted to the cerebral and cerebellar cortex and its covering leptomeninges. As the most important consequence, haemorrhagic infarcts and haemorrhages occurred in the subcortical white matter-that is, the region most vulnerable to impaired cortical circulation. Further development of these subcortical lesions gives rise to the fatal haemorrhages seen at necropsy. In so far as dementia occurs this is likely to result from multiple microinfarcts or haemorrhages. In most cases preamyloid lesions or diffuse plaques and early plaques were seen. No other type of plaque or neurofibrillary degeneration was found. The plaques occur in conjunction with the angiopathy, but may not occur even when the angiopathy is severe. In one patient plaques were totally absent. Angiopathy and plaques may be the result of the same mutation, the expression of which is governed by tissue factors or phenotypic differences between individual subjects.
\end{abstract}

\section{(F Neurol Neurosurg Psychiatry 1995;59:699-705)}

Keywords: cerebral haemorrhage; amyloidosis

Hereditary cerebral haemorrhage with amyloidosis, Dutch type (HCHWA-D), is an autosomal dominant condition afflicting members of four families from two coastal villages in The Netherlands. The most striking clinical and pathological manifestation is the occurrence of cerebral haemorrhage, mostly between the ages of 45 and 55, often recurring and multiple if not fatal. ${ }^{1-4}$ Dementia is also a manifestation of the disease in some patients, but brain atrophy is not a characteristic feature. ${ }^{245}$ The brains of deceased patients are characterised by excessive cerebral amyloid angiopathy, together with lobar haemorrhages and haemorrhagic infarcts. ${ }^{2-4}$ Amyloid is not found elsewhere in the body. The amyloid protein $(A \beta)$ has been shown to be similar to the cerebrovascular and senile plaque amyloid found in patients with Alzheimer's disease,
Down's syndrome and in non-demented elderly people. ${ }^{6-10}$ This amyloid protein is part of a larger precursor protein $(\beta \mathrm{PP})$, and in HCHWA-D, a mutation occurs in the $\beta$ PP gene. ${ }^{11}$ In HCHWA-D, senile plaques of a diffuse type, also called preamyloid lesions and early plaques, have been found. ${ }^{3}$ We now report the accumulated clinical and neuropathological findings in 63 patients with HCHWA-D.

\section{Material and methods}

The medical records of 63 patients belonging to families with HCHWA-D were studied. Most of the patients were treated between 1952 and 1992 in the departments of neurology and neurosurgery of the Leiden University Hospital and the Municipal Hospital of the Hague. For the others information was obtained from several other hospitals. In 36 patients histological confirmation was obtained from necropsy (30), including spinal cord (six) or brain biopsies (six). The mutation was also established in two other patients. These 38 patients comprise group A. In the remaining 25 cases one or more haemorrhages had been established by CT, lumbar puncture, or operation (group B). For comparison, five brains from patients with sporadic cerebral haemorrhage with amyloid angiopathy, 10 brains from patients with Alzheimer's disease and Down's syndrome, and 25 brains from age matched nondemented persons were studied. Formalin fixed brains and spinal cords were sectioned coronally and horizontally respectively. Tissue blocks were cut from the cortex and the white matter of the cerebrum and cerebellum, the brainstem and the spinal cord with their arachnoidea, and from the basal ganglia, the hippocampus, the chorioid plexus, and the basal cerebral arteries. Several staining methods were used on the sections of the paraffin embedded material, including Congo red and thioflavine-S to identify amyloid. Sections from patients with HCHWA-D, Alzheimer's disease, and sporadic cerebral haemorrhage with amyloid angiopathy were also stained by immunohistochemical methods for polyclonal antibody against a synthetic peptide identical to the 28 amino terminal residues of $\mathrm{A} \beta$ peptide (anti-SP28).

\section{Results}

CLINICAL STUDIES

Figures 1 and 2 show the age and sex distributions for both groups of patients. Age refers to 


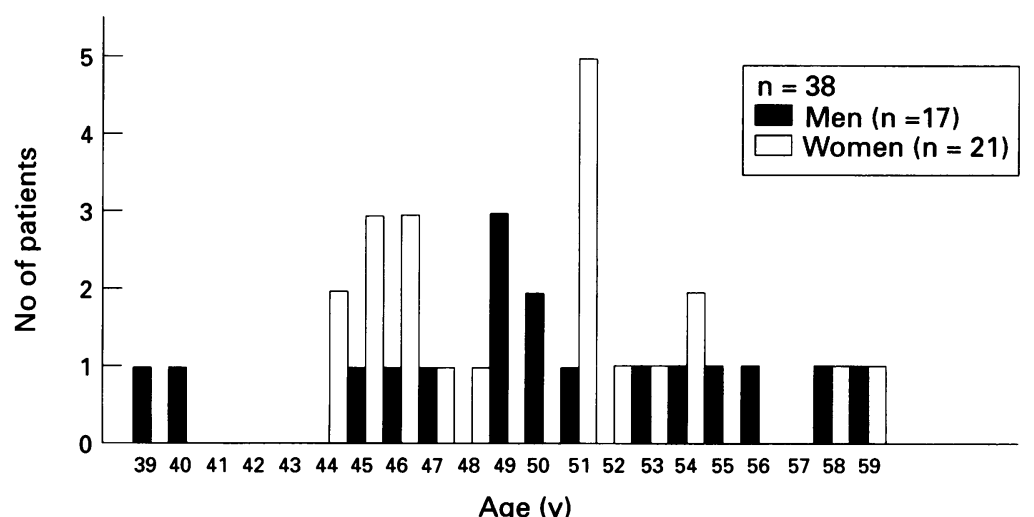

Figure 1 Histologically or genetically established cases of HCHWA-D. Ages refer to first clinical stroke.

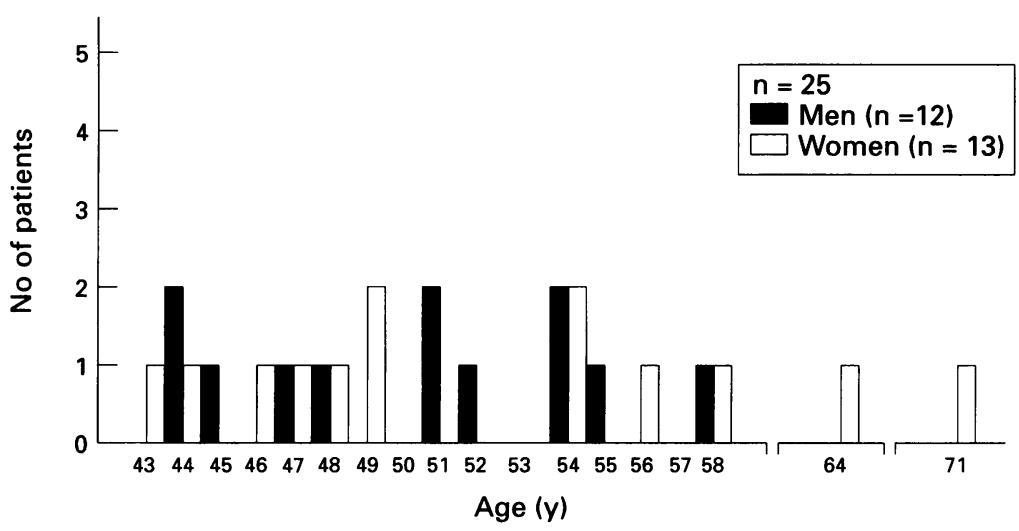

Figure 2 Cases of HCHWA-D with definite haemorrhage but without histological verification. Ages refer to first clinical stroke.

the year of the first recorded clinical manifestation of a stroke. In most patients it occurred between the ages of 45 and 55 . The two elderly patients in group B are included as probable cases because they had had two divergently located haemorrhages within one year. The mean age (SD) for the combined groups was $50.4(5.6)$ years (median 50 years). For group A these figures were $49 \cdot 8$

Table 1 Signs on admission

\begin{tabular}{llr}
\hline & \multicolumn{2}{l}{ Group } \\
\cline { 2 - 3 } Signs & $A$ & $B$ \\
\hline Coma & 18 & 11 \\
Impaired consciousness & 19 & 15 \\
Hemiparesis & 37 & 37 \\
Hemianopia & 19 & 21 \\
Aphasia & 16 & 6 \\
Apraxia & 3 & 2 \\
Agnosia & 5 & 3 \\
\hline
\end{tabular}

Table 2 Location of lobar haemorrhages

\begin{tabular}{lc}
\hline Location & No of lobar haemorrhages \\
\hline Frontal & 14 \\
Frontotemporal & 4 \\
Frontoparietal & 7 \\
Temporal & 21 \\
Temporoparietal & 12 \\
Temporo-occipital & 6 \\
Parietal & 13 \\
Parieto-occipital & 9 \\
Occipital & 20 \\
\hline
\end{tabular}

$(4 \cdot 8)$ years (median 50.5 years) and for group B $51.4(6.5)$ years (median 51 years). In the total material there was a female to male ratio of $5: 4$.

\section{MEDICAL HISTORY}

Twenty three patients had a history of headache, which had begun a few years or months before the first stroke in 10. In eight patients the headaches were of a migrainous nature, and in three of them were temporarily accompanied by one sided neurological signs. In two patients the first stroke resulted in a neurological deficit on the same side as had been affected by the previous migrainous attacks. Five of the patients with migrainous attacks belonged to one family; however, in this family, migraine seems to run also as an unrelated condition. Twenty six patients had transitory neurological symptoms either with or without headache, whereas in the remaining 37 no such events were recorded. A history of arterial hypertension or of overt mental decline was recorded in only a few patients.

SIGNS ON ADMISSION (TABLE 1)

In about $17 \%$ of the total number of strokes the onset was subacute, the symptoms and signs evolving over a period of one or several days. Three patients had a haemorrhage related to a head injury.

NUMBER OF STROKES AND INVESTIGATIONS

In total 86 strokes were documented in 38 group A patients and 64 in 25 group B patients. Haemorrhages corresponding to these strokes as shown by CT, lumbar puncture, biopsy, or necropsy numbered 70 in group A and 50 in group B. The discrepancy between the number of strokes and haemorrhages shown to be their cause may be due to the absence of CT in the earlier investigations. Nevertheless, the finding of a haemorrhage in about four out of five clinical strokes in both groups indicates that a stroke in a patient with HCHWA-D is most likely to be caused by a haemorrhage. Table 2 shows the distribution of lobar cerebral haemorrhages. There was one (fatal) cerebellar haemorrhage in group A. Infarcts accounting for a stroke were found on four CT scans. Lumbar puncture was performed on 57 occasions and yielded bloody or xanthochromic CSF in 46 instances. Fifty angiograms were either normal (22) or indicative of a space occupying lesion.

\section{CLINICAL COURSE}

Eighteen patients $(28.6 \%)$ died within a year of their first recorded haemorrhage, half of them within two weeks. There was great variation in the number of clinical strokes and haemorrhages (one to 10) and the interval between them (days to years). Operations were performed 29 times. Four patients died within one day after the operation, seven after two to 14 days, and the others survived months to years; the longest recorded survival was 22 years. Surviving patients with small lobar haemorrhages were well until the next 
Figure 3 Subcortical infarct (haematoxylin and eosin $\times 45)$.

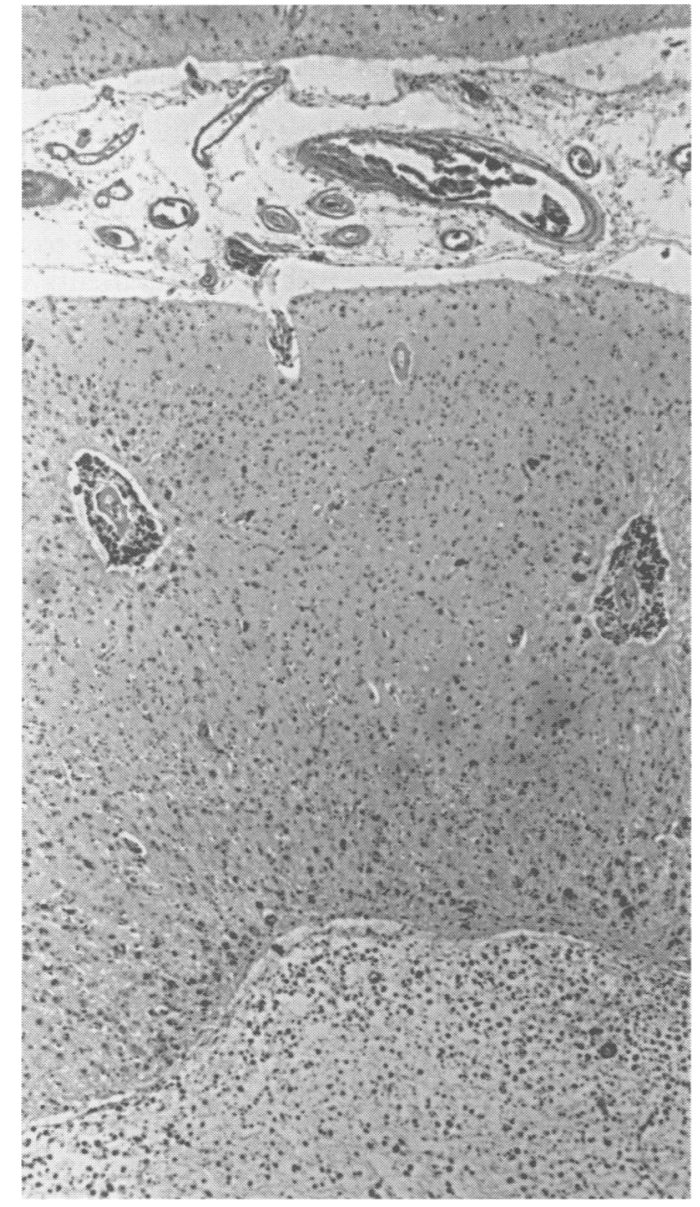

stroke, or became increasingly incapacitated with recurring strokes. One patient became gradually demented and initially was diagnosed as having Alzheimer's disease.

\section{NEUROPATHOLOGICAL EXAMINATION \\ Macroscopy}

None of the brains showed atrophy. The leptomeninges sometimes exhibited local thickening or haemorrhagic infiltration with brownish discoloration of the brain surface. The basal arteries were not conspicuously atherosclerotic. Macroscopic sections often showed remnants of old cortical and subcortical haemorrhages or infarcts as well as one or more fresh haemorrhages.

\section{Microscopy}

The microscopic abnormalities were identical in all HCHWA-D cases. They were restricted to the brain and its meninges; none were found in any of the visceral organs.

\section{HAEMORRHAGES AND INFARCTS}

Both recent and old haemorrhages were found in the brain and in the leptomeninges. In the brain they were mostly in the deeper cortical layers and in the subcortical white matter. Haemorrhagic infarcts, incomplete infarcts, and their remnants were also found in the cortex and subcortical white matter (fig 3 ); these often resulted in cleft-like lesions running parallel to the border between cortex and white matter. Occasionally the affected cortex showed scattered loss of ganglion cells accompanied by satellitosis and astroglia proliferation. Subcortically the white matter showed some demyelination, occasionally accompanied by ill defined areas of incomplete infarction and disappearance of perivascular brain substance. Perivascular bleeding and the presence of siderophages as well as incrustation of vessel walls with hemosiderin were found, mainly in the neighbourhood of the transition of normally structured, dilated vessels to sclerotic vessels. Sometimes an organised or recanalised thrombus was present in these vessels. The extravasations occurred throughout the cortex, and only sporadically around arachnoideal and subcortical vessels. They were often in communication with the subcortical cleft-like infarcts. Remnants of infarcts, haemorrhages, and vascular leakage of blood were found in cases with longstanding disease. The brains of patients who died from their first accident, on the other hand, showed only amyloid angiopathy and a few small haemorrhagic infarcts apart from the fresh bleeding.

\section{ANGIOPATHY}

All staining procedures showed pronounced vascular abnormalities-namely, concentrically thickened walls with a homogeneous texture and few or no nuclei. The lumina were often very reduced or nearly obliterated. When viewed in polarised light after Congo red staining the vessel walls showed green birefringence and with violet light after thioflavine-S staining they exhibited yellow fluorescence. These procedures showed the presence of amyloid to be confined to the adventitia and media of the vessel wall. The angiopathy was found in the cerebral and, to a much lesser extent, cerebellar cortex, and their covering arachnoidea. In the cortex arterioles and, locally, capillaries were affected, whereas in the arachnoidea this was limited to arteries. The involved arachnoidal vessels sometimes showed tortuosity and "double barrelled" sclerosis; however, obviously normal arteries also showed amyloid deposits. By contrast with a greater tendency towards temporal and occipital localisation of haemorrhages, angiopathy did not show a preference for any cortical lobe or layer, where it was present in clusters or occurred diffusely. The diffusion gave the impression that almost all arterioles were abnormal (see fig 5). In $7 \mu \mathrm{m}$ tissue sections, their numbers varied between $1-25 / \mathrm{mm},{ }^{2}$ but most of the counts did not exceed $10 / \mathrm{mm}^{2}$ The angiopathy was absent in the basal ganglia, the cerebral and cerebellar white matter, and in the brainstem and spinal cord and their arachnoidea. The abnormal vessels were clearly labelled with anti-SP28, both without and after pretreatment with formic acid.

\section{DIFFUSE PLAQUES (PREAMYLOID LESIONS)}

Although Bielschowsky, Holmes, and Palmgren stains generally failed to show senile plaques, many black or brown plaque-like lesions were present in preparations stained 


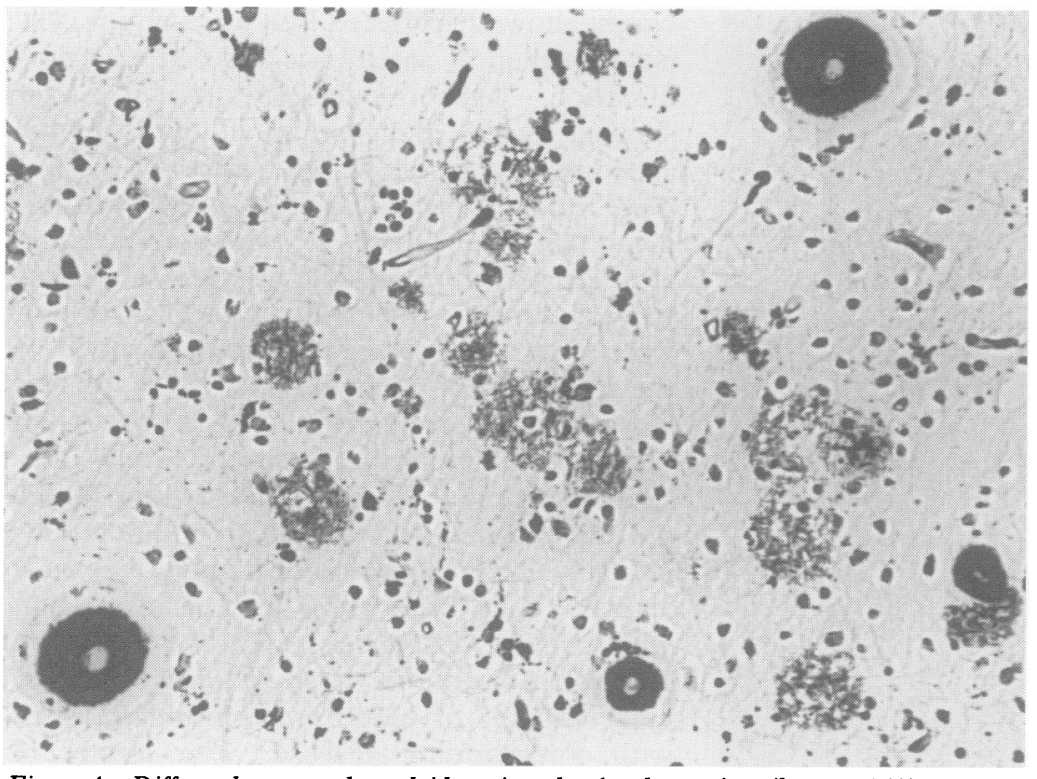

Figure 4 Diffuse plaques and amyloid angiopathy (methenamine-silver $\times 150$ )

with methenamine-silver. They consisted of sometimes round or oval, but mostly irregularly shaped, homogeneous structures. Their diameters ranged from 20 to $150 \mu \mathrm{m}$, predominantly about $75-100 \mu \mathrm{m}$ (fig 4 ). These diffuse plaques lacked the central amyloid core of classic senile plaques. In high magnification they consisted of intermingled fibres or short rods of varying thickness. In many instances fibres were hardly discernable from the background, the lesions giving the impression of local condensation of the neuropil or even only enhanced argyrophilia of the neuropil. Their configuration was different from

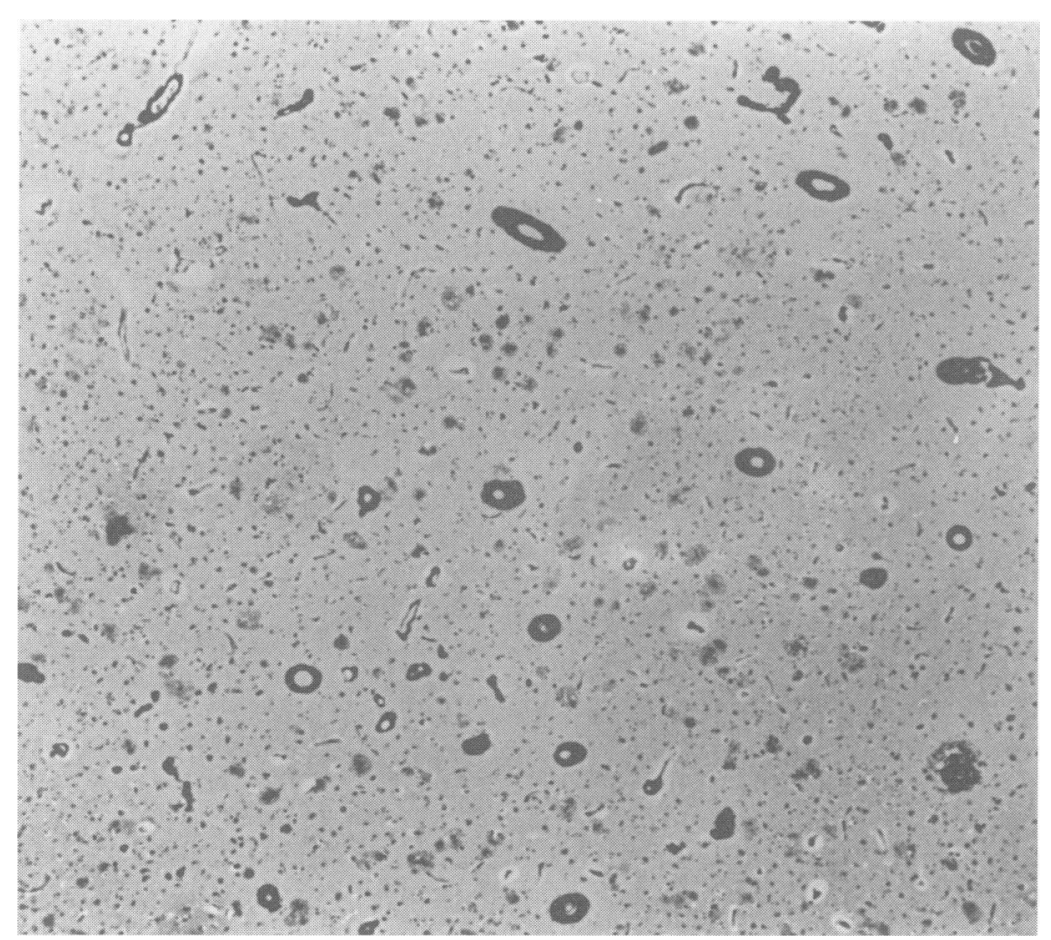

Figure 5 Co-occurrence of abundant diffuse plaques and amyloidotic vessels (methenamine-silver $\times 30)$ neurofibrillary tangles, the characteristic finding in Alzheimer's disease. They could also easily be visualised as spots of a slightly darker green against the lighter background or as bright yellow-green spots with the thioflavine$S$ method. Both methods identified similar lesions in addition to the classic senile plaques in brains of patients with Alzheimer's disease or Down's syndrome. In 22 of the 25 control cases no plaques were found after staining with methenamine or any of the other silver stains employed (Bielschowsky, Bodian, Holmes, and Palmgren). Classic plaques were rarely found in HCHWA-D. The number of these diffuse plaques in the patients with HCHWA-D varied much more than the angiopathy. They were found in all cerebral lobes and cortical layers, locally or disseminated, varying from 2 to $50 / \mathrm{mm}^{2}$. The plaques were seldom seen in the hippocampus and were absent from the basal ganglia, the brainstem, the spinal cord, and the cerebellum. Although the plaques showed a distribution similar to the angiopathy, a spatial or numerical correlation was not evident. Notably, plaques could be totally absent in slides showing many abnormal vessels, whereas in other areas they co-occurred (figs 5 and 6). In one patient plaques were totally absent. In frozen sections Anti-SP28 stained the blood vessels as well as the senile plaques. In paraffin sections vessels were always stained, but senile plaques only after pretreatment with formic acid and trypsin. Table 3 summarises the tinctorial and immunohistochemical properties of plaque type and cerebral amyloid angiopathy in HCHWA-D and Alzheimer's disease.

NEUROFIBRILLARY DEGENERATION

Neurofibrillary tangles were not encountered in brains from patients with HCHWA-D.

\section{Discussion}

Hereditary cerebral haemorrhage with amyloidosis, Dutch type (HCHWA-D) is a unique, autosomal dominant disorder, involving the meningocortical microvasculature. The afflicted vessels show amyloid deposition in the vessel walls, which categorises the disease as a form of localised cerebral amyloidosis. Later on these vessels become gradually more sclerotic. This pathology usually results in recurrent, sometimes multiple, lobar haemorrhages. Rupture into the subarachnoid space often occurs, and to a limited extent also into the ventricles. This is exemplified by the finding of bloody or xanthochromic CSF in about $80 \%$ of lumbar punctures. By contrast with a predominance of haemorrhages in the frontal lobe in sporadic cerebral haemorrhage with amyloid angiopathy, the temporal and occipital lobes are mostly involved in HCHWA-D (table 2). ${ }^{12}$ Surgical intervention in the presence of cerebral amyloid angiopathy has been described as hazardous because of brittleness and lack of contractility of the sclerotic vessels, but this was not confirmed in a larger series of patients. ${ }^{1314}$ The results in patients with HCHWA-D seem to be in agreement 


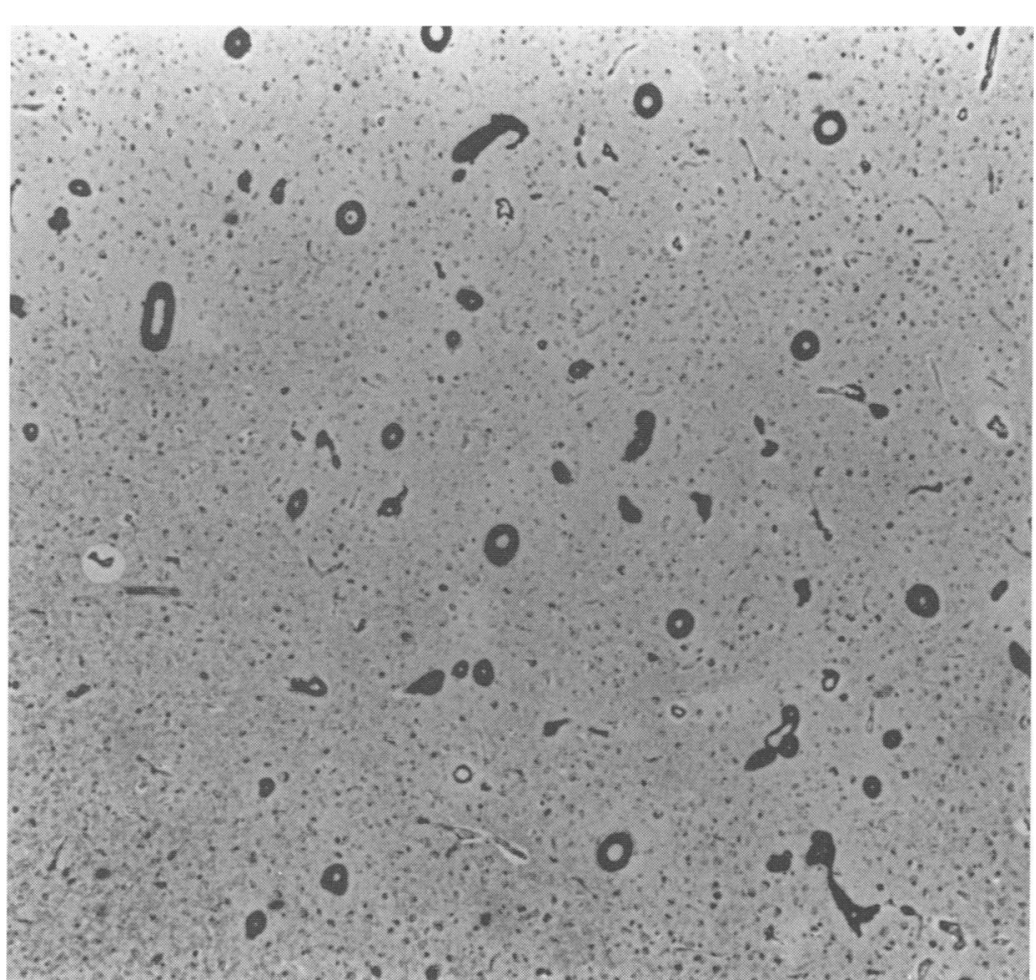

Figure 6 Severe amyloid angiopathy, but diffuse plaques are absent. Same patient as fig 5 (methenamine-silver $\times 30)$.

with the later report. A similar disorder has been found in Icelandic families (HCHWAI). ${ }^{15}$ The Icelandic patients are considerably younger, having their strokes at a mean age of $27 \cdot 3$ years $v 50 \cdot 44$ for the Dutch patients. In both disorders, dementia can occur in the years after the first stroke. In HCHWA-D dementia can even be the only clinical expression of the disease. ${ }^{5}$ Important differences exist with regard to the respective amyloid compositions and the occurrence of senile plaques in HCHWA-D as opposed to HCHWA-I. In HCHWA-I, the amyloid is a variant of the proteinase inhibitor cystatin-C, whereas in HCHWA-D it is mainly composed of a variant of the $A \beta$ peptide, which is a normal proteolytic fragment of $\beta$ PP. ${ }^{17-19}$ The soluble form of $\beta \mathrm{PP}$ (designated nexin II) is also a proteinase inhibitor. ${ }^{20}$ The colocalisation of $\mathrm{A} \beta$ amyloid and cystatin $\mathrm{C}$ amyloid in both hereditary and sporadic cerebral amyloid angiopathy has been reported..$^{21} \mathrm{~A} \beta$ Amyloid is also found in vessels and senile plaques in Alzheimer's disease, Down's syndrome, and

Table 3 Tinctorial properties of plaque types and amyloid angiopathy (CAA) in Alzheimer's disease (AD) and HCHWA-D (in paraffin embedded tissue)

\begin{tabular}{|c|c|c|c|c|c|}
\hline & \multirow{2}{*}{$\begin{array}{l}\text { Classic senile plaques } \\
\text { (sporadic in HCHWA-D) } \\
A D\end{array}$} & \multicolumn{2}{|c|}{$\begin{array}{l}\text { Non-classic senile plaques } \\
\text { (primitive, diffuse) }\end{array}$} & \multicolumn{2}{|c|}{$C A A$} \\
\hline & & $A D$ & $H C H W A-D$ & $A D$ & $H C H W A-D$ \\
\hline Bielschowsky & + & + & - & + & + \\
\hline Congo red & + & - & - & + & + \\
\hline Methenamine & + & + & + & + & + \\
\hline Thioflavine-S & + & + & + & + & + \\
\hline AA $\beta$ & + & + & - & + & + \\
\hline $\mathrm{AAb} / \mathrm{FA}$ & + & + & + & + & + \\
\hline
\end{tabular}

$\mathrm{AA} \beta=$ antibody against $\mathrm{A} \beta$ amyloid; $\mathrm{AA} \beta / \mathrm{FA}=$ antibody against $\mathrm{A} \beta$ amyloid after pretreatment with formic acid and trypsin. sporadic cerebral haemorrhage with amyloid angiopathy, and often in asymptomatic aged persons. Apart from these conditions, cerebral amyloid angiopathy is found in a variety of disorders. ${ }^{12}$ These comprise familial and sporadic degenerative afflictions of the CNS as well as miscellaneous disorders. As in HCHWA-D and HCHWA-I, amyloid in most of these cases is confined to the CNS, which is rarely involved in systemic amyloidosis. The chemical nature of the amyloid in the aforementioned conditions is largely unknown, with the exception of spongiform encephalopathies, where it is proteinase resistant protein, and in cerebral arteriovenous malformations, in which immunohistochemical analysis has shown it to be $\mathrm{A} \beta$ amyloid. ${ }^{23}$ Because cerebral amyloid angiopathy occurs increasingly with advancing age, its coexistence with various brain diseases in elderly people need not necessarily point to a pathogenetic relation. The amyloid angiopathy of HCHWA-D closely resembles that in Alzheimer's disease, Down's syndrome, and elderly people, both in its distribution and its chemical composition. It is most severe, however, in HCHWA-D, as reflected in the tendency towards cerebral haemorrhage, which is absent in the other conditions, with the exception of sporadic cases of cerebral haemorrhage with amyloid angiopathy. Cerebral amyloid angiopathy in Alzheimer's disease is variable and often inconspicuous.

The pathogenesis of the lobar haemorrhages is unexplained. Our histopathological studies do not point to a simple rupture of abnormal vessels as the only cause of haemorrhages. Additional microscopic findings that are present in longstanding cases, however, may offer some clue. The immediately subcortical white matter functions as a terminal or watershed region between the cortex and the deeper medulla. The white matter is supplied by long penetrating cortical arteries, which are also involved in the amyloidosis. ${ }^{24}$ So when the number of these vessels with stenosed or nearly obliterated lumina increases, subcortical split-like infarctions may result. The small perivascular bleedings, which are found mainly at the border between the sclerotic and normal, sometimes dilated, portions of the vessels, may result in larger haemorrhages when they are in contact with the split-like infarcts. Locally raised blood pressure as a result of increased resistance in the cortical distally narrowed vessels may facilitate rupture or leakage of the normal or angiopathic vessels entering the subcortical infarcts. In patients with a large, often fatal haemorrhage as the first and only manifestation, such a rupture seems to be the only explanation. In these cases a sudden rise in blood pressure in the absence of longstanding systemic hypertension may have contributed to the rupture. A similar mechanism has also been proposed for some cases of spontaneous cerebral haemorrhage. Furthermore, those patients with HCHWA-D and migraine who had a haemorrhage during a migrainous attack, seem to provide arguments in favour 
of the theory with regard to the sporadic occurrence of cerebral haemorrhage during a bout of migraine. ${ }^{25}$ The proposed mechanism for this is the reperfusion of tissue rendered vulnerable by ischaemia. In HCHWA-D migraine would further compromise local borderline or deficient perfusion caused by the angiopathy.

It is not clear whether HCHWA-D is a vascular variant of Alzheimer's disease, or a different disease having $A \beta$ amyloid deposition in common with Alzheimer's disease. Brain atrophy and neurofibrillary tangles are absent in HCHWA-D, regardless of the duration of the disease and the number of senile plaques. In most patients dementia is not the presenting symptom in HCHWA-D. When it becomes conspicuous it does so in the course of repeated cerebrovascular accidents. It is likely to be the result of the profuse occurrence of cortical and subcortical microinfarcts - that is, multi-infarct dementia. Senile plaques do occur in HCHWA-D, but only the diffuse type; more mature forms ("classic" and "burned out") are absent. They are only visible with special staining techniques. In Alzheimer's disease immunostaining of senile plaques is enhanced by pretreatment with formic acid. ${ }^{26}$ In HCHWA-D the senile plaques are also stained by anti-SP28 after pretreatment of paraffin embedded tissue with formic acid and trypsin. In cryostat sections antibody against native $\mathrm{A} \beta$ amyloid labels senile plaques in HCHWA-D. ${ }^{27}$

The aetiological or pathogenetic role of the $\mathrm{A} \beta$ amyloid in the development of the socalled $\beta$ amyloidoses has not yet been fully elucidated. In HCHWA-D a mutation in the $\beta \mathrm{PP}$ gene has been found (glutamine for glutamic acid at position 22). ${ }^{11}$ This substitution was not found in unaffected subjects; nor was it found in sporadic or familial Alzheimer's disease. Thus the conclusion that amyloid formation in the abnormal vessels in HCHWA-D is not a secondary phenomenon or unrelated polymorphism, but rather the cause of the angiopathy, seems to be warranted.

Another question concerns the relation between cerebral amyloid angiopathy and senile plaques. In sporadic cerebral amyloid angiopathy with and without haemorrhage and in Alzheimer's disease a regional dissociation of cerebral amyloid angiopathy and plaques or the total absence of plaques occurs and this is also the case in HCHWA-D. ${ }^{28-31}$ If the senile plaques in HCHWA-D represent amyloid accumulation, then the dissociation between cerebral amyloid angiopathy and senile plaques seems to suggest that amyloid depositions in vessel walls and parenchyma evolve independently. These are caused by the same genetic defect, the expression of which is governed by local factors. These factors may differ not only regionally within subjects, but also between subjects. Alternatively, preamyloid lesions or diffuse plaques are the result of alterations in the blood-brain barrier.
We thank Mrs Keller for secretarial assistance.

1 Luyendijk W, Schoen JHR. Intracerebral haematomas. A clinical study of 40 surgical cases. Psychiatria, Neurologia, Neurochirurgia 1964;67:445-68.

2 Wattendorff AR, Bots GThAM, Went LN, Endtz LJ. Familial cerebral amyloid angiopathy presenting as recurrent cerebral hemorrhage. If Neurol Sci 1982; 55:121-35.

3 Luyendijk W, Bots GThAM, Vegter-van der Vlis M, Went LN, Frangione B. Hereditary cerebral hemorrhage caused by cortical amyloid angiopathy. $\mathcal{F}$ Neurol Sci 1988;85:267-80.

4 Wattendorff AR. Clinical and neuropathological studies in hereditary cerebral hemorrhage with amyloid angiopathyhereditary cerebral hemorrhage with amyloid angiopat
Dutch type [thesis] Leiden: Leiden University, 1991.

Dutch type [thesis] Leiden: Leiden University, 1991.
5 Haan J, Lanser JBK, Zuyderveld I, van der Does GF, Roos RAC. Dementia in hereditary cerebral hemorrhage with RAC. Dementia in hereditary cerebral hemorrhage with

6 Glenner GG, Wong CW. Alzheimer's disease and Down's syndrome: sharing of a unique cerebrovascular amyloid fibril protein. Biochem Biophys Res Commun 1984;122: 1131-5.

7 Wong CW, Quaranta V, Glenner GG. Neuritic plaques and cerebrovascular amyloid in Alzheimer disease are antigenically related. Proc Natl Acad Sci USA 1985; 82:8729-932.

8 Pardridge WM, Vinters HV, Yang J, Eisenberg J, Choi TB, Tourtellotte WW, et al. Amyloid angiopathy of Alzheimer's disease: amino acid composition and partial Alzheimer's disease: amino acid composition and partial
sequence of a 4.200-Dalton peptide isolated from cortical sequence of a $4 \cdot 200$-Dalton peptide isolated from
microvessels. $\mathcal{F}$ Neurochem 1987;49:1394-401.

9 Coria F, Castano EM, Frangione B. Brain amyloid in normal aging and cerebral amyloid angiopathy is antigenically related to Alzheimer's disease $\beta$-protein. $A m \mathcal{F}$ Pathol 1987;129:422-8.

10 Coria F, Prelli F, Castano EM, Larrondo-Lillo $M$, Fernandez-Gonzalez J, van Duinen SG, et al. $\beta$-Protein deposition: a pathogenetic link between Alzheimer's disease and cerebral amyloid angiopathies. Brain Res 1988;463: 187-91.

11 Levy E, Carman M, Fernandez-Madrid J, Power MD, Lieberburg I, van Duinen SG, et al. Mutation of the Alzheimer's amyloid gene in hereditary cerebral hemorrhage, Dutch type. Science 1990;248:1124-6.

12 Vinters HV. Cerebral amyloid angiopathy. A critical review. Stroke 1987;18:311-24.

13 Torack RM. Congophilic angiopathy complicated by surgery and massive hemorrhage. A light and electron microscopic study. Am F Pathol 1975;81:349-66.

14 Leblanc R, Preul M, Robitaille Y, Nillemure J, Pokrupa R. Surgical considerations in cerebral amyloid angiopathy. Neurosurgery 1991;29:712-8.

15 Gudmundsson G, Hallgrimsson J, Jonasson TA, Bjarnasson O. Hereditary cerebral hemorrhage with amyloidosis. Brain 1972;95:387-404.

16 Jensson $O$, Gudmundsson G, Arnason A, Blöndal $H$, Grubb A, Löfberg $H$. Hereditary central nervous system gamma-trace amyloid angiopathy and stroke in Icelandic families. In: Glenner GG, Osserman EF, Benditt EP, families. In: Glenner GG, Osserman EF, Benditt EP, Amyloidosis. New York: Plenum Publishing Corporation, 1986:789-801.

17 Cohen DH, Feiner H, Jensson O, Frangione B. Amyloid fibril in hereditary cerebral hemorrhage with amyloidosis (HCHWA) is related to the gastro-enteropancreatic (HCHWA) is related to the gastro-enteropancreatic
neuro-endocrine protein, gamma-trace. $f$ Exp Med neuro-endocrine

18 Ghiso J, Jensson O, Frangione B. Amyloid fibrils in hereditary cerebral hemorrhage with amyloidosis of Icelandic type is a variant of gamma-trace basic protein (cystatin C). Proc Natl Acad Sci USA 1986;83:2974-8.

19 Palsdottir A, Thorsteinsson L, Olafson I, Abrahamson M, Arnason A, Grubb A. Mutation in cystatin C gene causes hereditary brain hemorrhage. Lancet 1988;ii: 603-4.

20 Selkoe DJ. The molecular pathology of Alzheimer's disease. Neuron 1991;6:487-98.

21 Vinters HV, Secor DL, Pardridge WM, Gray F. Immunohistochemical study of cerebral amyloid anmunohistochemical study of cerebral amyloid bral microvessel walls colocalizes with gamma trace in bral microvessel walls colocalizes with gamma trace in patients with leuko-encephalopathy. Am Neurol 1990;28: 34-42.

22 Haan J, Roos RAC. Coexistence of cystatin $C$ and $\beta$ protein immunoreactivity. Stroke 1990;21:1510.

23 Hart MN, Merz P, Bennet-Gray J, Menezes AH, Goeken JA, Schelper RL, Wisniewski HM. $\beta$-Amyloid protein of Alzheimer's disease is found in cerebral and spinal cord vascular malformations. Am F Pathol 1988;132:167-72. 24 Pfeifer RA. Die Angioarchitektonische Areale Gliederung der Groszhirnrinde. Leipzig: Georg Thieme, 1940.

25 Caplan L. Intracerebral hemorrhage revisited. Neurology 1988;38:624-7.

26 Kitamoto T, Ogomori K, Tateishi J, Prusiner SB. Formic acid pretreatment enhances immunostaining of cerebral and systemic amyloids. Lab Invest 1987;57:230-6.

27 Rozemuller JM, Roos RAC, Bots GTAM, Kamphorst W, Eikelenboom P, Van Nostrand, WE. Distribution of 
B/A4 protein and amyloid precursor protein in hereditary cerebral hemorrhage with amyloidosis-Dutch type and Alzheimer's disease. Am $\mathcal{F}$ Pathol 1993;142:1449-57.

28 Mandybur TI. The incidence of cerebral amyloid angiopa thy in Alzheimer's disease. Neurology 1975;25:120-6.

29 Julien J, Vital C, Lagueny A, Ferrer X, Vital A. Hémorrhagie cérébrale récidivante et angiopathie amyloïde. Rev Neurol (Paris) 1983;139:763-7.
30 Eikelenboom P, Stam FC. An immunohistochemical study on cerebral vascular and senile plaque amyloid in Alzheimer's dementia. Virchows Arch B Cell Pathol 1984;47:17-25.

31 Michel B, Gastaut JL, Gambarelli D, Chave B. Hématomes intracérébraux lobaires récidivants au cours de l'angiopathie amyloide cérébrale. Rev Neurol (Paris) 1988;144:503-7.

\section{NEUROLOGY IN LITERATURE}

\section{Some strokes}

Bennett was some 70 years early in his dating of the onset of the declining incidence of stroke. The combination of ptosis and contralateral hemiplegia (or Weber's syndrome) was, according to Kinnier Wilson, a not uncommon manifestation of cerebral syphilis. Glossolabiolaryngeal paralysis was first described under a slightly different title, by Duchenne as a progressive disorder of uncertain aetiology. Sophie's symptoms begin abruptly, almost certainly as a consequence of cerebrovascular disease. They have some resemblance to the bulbar features of the lateral medullary syndrome, although tongue paresis would imply medial medullary involvement.

Vidal's mother, in the Kipling short story, is lockedin, a condition which has received considerable attention in literature, most notably by Zola in Thérèse Raquin and Dumas in the Count of Monte Cristo.

Gustave Flaubert, 1856-7, Madame Bovary

Monsieur Bovary senior had indeed met his end, quite suddenly, two days ago. He had been seized with a stroke after dinner.

George Eliot, 1859, Adam Bede

"Satchell's got a paralytic stroke. I found it out from the lad they sent to Treddleston for the doctor, before seven o'clock this morning. He's a good way beyond sixty, you know; it's much if he gets over it."

George Eliot, 1866, Felix Holt

But he had now the unevenness of gait and feebleness of gesture which tell of a past paralytic seizure.

Rudyard Kipling, undated, Dayspring mishandled Manallace made a reputation, and, more important, money for Vidal's mother after her husband ran away, and the first symptoms of her paralysis showed...

Vidal's mother was then wholly paralysed. Only her eyes could move, and those always looked for the husband who had left her.

Amold Bennett, 1908, The old wives' tale

She was aged four when John Baines had suddenly been seized with giddiness on the steps of his shop, and had fallen, and, without losing consciousness, had been transformed from John Baines into a curious and pathetic survival of John Baines. She had no notion of the thrill which ran through the town on that night when it was known that John Baines had had a stroke, and that his left arm and left leg and his right eyelid were paralysed. ... She knew him simply as an organism on a bed, whose left side was wasted, whose eyes were often inflamed, whose mouth was crooked, who had no creases from the nose to the corners of the mouth like other people, who experienced difficulty in eating because the food would somehow get between his gums and his cheek. ...

Arnold Bennett, 1908, The old wives' tale

"Fossett!" She tried to call out; but no sound issued from her lips. She could not move her tongue. She tried to protrude it, and could not. . . .

Suddenly she began to hiccough, and she had no control over the hiccough. ...

Sophie began to feel better. She could get into a sitting posture, though the movement made her dizzy. By working to the foot of the bed she could see herself in the glass of the wardrobe. And she saw that the lower part of her face was twisted out of shape.

The doctor, who knew her, and who earned a lot of money in her house, told her frankly what had happened. Paralysie glosso-labiolaryngee was the phrase he used.

\section{Amold Bennett, 1911, Hilda Lessways}

A paralytic stroke had not been drastic enough to mar Mr Skellorn's most precious reputation for probity and reliability. ...

Although paralytic strokes were more prevalent at that period than now, they constituted even then a striking dramatic event. Moreover, they were considered as direct visitations of God. Also there was something mysteriously and agreeably impressive in the word "paralytic", which people would repeat for the pleasure of repeating it. ...

"Yes," she said, "They came and fetched me out of my bed at three o'clock this morning; and would you believe me, though he couldn't hardly speak, the money and this here book was all waiting in his desk, and he would have me come with it!. . .

And I do believe if he'd been paralysed on both sides instead of only all down his right side, and speechless too, he'd ha' made me understand as I must come here at two o'clock."

Edith Wharton, 1920, The age of innocence .... had found their mistress sitting up against her pillows with a crooked smile on her face and one little hand hanging limp from its huge arm.

The stroke had clearly been a slight one, for she was able to articulate and to make her wishes known; and soon after the doctor's first visit she had begun to regain control of her facial muscles.

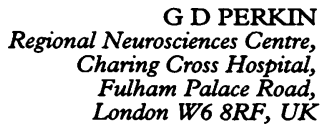

